\title{
The Turkish real time kinematic GPS network (TUSAGA-Aktif) infrastructure
}

\author{
Cetin Mekik $^{1 \star}$, Omer Yildirim² and Sedat Bakici ${ }^{2}$ \\ ${ }^{1}$ Department of Geodesy and Photogrammetry, Engineering Faculty, Karaelmas University, Zonguldak, Turkey. \\ ${ }^{2}$ Land Registration and Cadastre, Photogrammetry and Geodesy Administration, Ankara, Turkey.
}

Accepted 3 June, 2011

\begin{abstract}
The concept of Real Time Kinematic (RTK) Network has become popular throughout the world since the beginning of 2000s. The RTK Network server collects satellite observations from the RTK Network, performs calculations and sends RTK corrections to the rover. Thus, these RTK Networks eliminates the need for post-processing GPS observations; instead the users in the field instantaneously obtain the receiver antenna's three dimensional coordinates with $\mathrm{cm}$ accuracy. This paper details the infrastructure of the Turkish RTK CORS Network called TUSAGA-Aktif established by Istanbul Kultur University in association with the General Directorate of Land Registration and Cadastre and the general command of mapping and sponsored by the Turkish Scientific and Technical Research Agency (TUBITAK). The network constitutes 146 Continuously Operating Reference Stations controlled by the two control stations, the Master Control Station at the Photogrammetry and Geodesy Administration of the general directorate of land registration and cadastre and the auxiliary control station at the headquarters of the general command of mapping both in Ankara, the capital city of Turkey.
\end{abstract}

Key words: Continuously operating reference stations, real time kinematic network, control stations.

\section{INTRODUCTION}

Surveyors, geographic information system (GIS) designers and users, engineers, geomatics and earth scientists and to sum it all public making use of GPS data have begun to use continuously operating reference stations (CORS) networks for the last two decades in most developed and some developing countries. These CORS Networks deliver global navigation satellite system (GNSS) data which support three dimensional positioning not only for surveyors but also for any works in need of high accuracy and time efficiency such as meteorologists, geophysical and geological engineers, construction engineers and so on (http://www.ngs.noaa.gov/CORS/). CORS have been implemented to contribute towards very high accuracy geodetic tasks since the late 1980s (Evans et al., 2002). Network based positioning provides geometric strength, reference datum stability and of course redundancy to geodetic methods; this is why CORS have become popular globally. Although these

\footnotetext{
${ }^{*}$ Corresponding author. E-mail: cmekik@hotmail.com.
}

CORS networks are extremely useful in providing high accuracy positioning, they are not time efficient, that is, it is not possible to obtain instantaneous accurate positions, requiring static positioning hours of point occupations and later post-processing. This made CORS networks unpopular for engineering-type surveys (Mekik, 2004). At the beginning of 2000 , the engineering and scientific community managed to add 'real time kinematic' positioning ability to their CORS networks (or rather passive/static CORS networks) and this made a worldwide breakthrough in concept and efficiency of positioning (Bock et al., 2002; Rizos et al., 2003; Eren, 2005; Rizos, 2007; Grejner-Brzezinska et al., 2007). These types of CORS Networks are called RTK CORS, CORS-Active and so on to distinguish them from the old type of passive CORS networks (Rizos et al., 2003; Wübbena and Willgalis, 2001; Retscher, 2002). CORS 'service provider', who sells user subscriptions, manages the CORS whose 'service provider, chooses the Network RTK method the server will use. Therefore, this choice will ultimately influence the quality of RTK solution that can be achieved at the rover. The CORS Network is 
designed to provide data to GPS rover receivers by continuously monitoring and correcting the positional data from the GNSS satellite constellations (URL 2). The transmission of the correction factors via the internet and monitoring and reporting the timing errors to the central computing component allows for real time correction and adjustment of the coordinates to allow the rover to perform its job higher level of accuracy (Lachapelle et al., 2002; Cruddace et al., 2002; Bray and Greenway, 2004). If RTK could be carried out in a perfect environment, with no atmospheric biases and no satellite orbit bias, there would be no need to restrict the range between a base station and the rover.

Unfortunately, the Earth's environment is never a perfect environment for GPS. This environment leads to distance dependant errors which restrict the range at which a rover can compute an RTK position fix. Atmospheric delays are the main error sources for medium-range relative positioning, hence the main challenge for a NRTK system is the computation and representation of atmospheric delay errors for users. The major difference between the methods is that they use different approaches to make corrections for the rovers (URL 2). Every CORS network consists of several GNSS stations interconnected by reliable communications to enable real time computations and control. Each station as a minimum requires a receiver, an antenna, communications and a power supply. In most cases a computer is installed additionally for data transmission and control. In ideal cases, a supplementary configuration is used for reliability or 'back up' reasons. Additionally a user interface is required to configure and maintain the network. This may be realized remotely for example, by radio communication or by mobile phones or via internet connection. An offline network that provides the information to the user for post-processing, the stored data files use 'RINEX' format (Wübbena and Willlgalis, 2001).

\section{METHODOLOGY OF RTK NETWORKS}

The RTK Network server collects satellite observations from the RTK Network, performs calculations and sends RTK corrections to the rover. There are a few RTK correction techniques available namely: Virtual Reference Station method, FKP method and MAC method (Wanninger, 2002). The Virtual Reference Station (VRS) corrections are optimized for the rover position at the beginning of the RTK session. If the rover then moves a considerable distance within the same session (that is, without disconnecting and reconnecting) the corrections might not be appropriate for the new rover location (Landau et al., 2003). With the Virtual Reference Station method the rover does not receive any observations related to a real reference station; instead all correction relating to rover's position comes from the virtual reference station (Wanninger, 1999; Vollath et al., 2000, 2001, 2002, 2003a; Roberts et al., 2004). The Flächen-Korrektur parameter or area correction parameters (FKP) method creates area correction parameters represented as simple planes (East- West and North-South gradients) that are valid for a limited area around a single reference station. The FKP method is a broadcast method and does not require the RTK rover to send its current position to the network central server (simplex communication suffices). Instead, the server models the distance dependant errors and sends RTK data from one reference station within the network to the rover, along with the model (Wübbena et al., 2001). In this method the server computes the network solution (so called FKP) to reduce the distance dependent errors. Thus the network solution is not optimized for the rover's position and might be limiting the RTK solution. In this method the correction parameters computed at the server are assumed that the distance dependent errors change linearly between reference stations. However, interpolation errors will occur at the rover if the true errors are non-linear. This can result in poor position quality or problems in the ambiguity fixing. To resolve this issue, the user can disconnect and start a new session to generate a new reference station, or the server may automatically generate a new reference station. However, (in either case) generating new reference stations can cause jumps in position and accuracy. Therefore, the user can end up with inconsistent positions and accuracies throughout their survey (Wubbena et al., 2001, 2004; Vollath et al., 2000, 2001, 2002, 2003b, 2004).

In the master auxiliary concept (MAC), the RTK Network server sends full raw observations and coordinate information for a single reference station, the Master Station, for all other stations in the network, the ambiguity-reduced data of every reference station. Therefore, it maximizes the use of all satellite data to calculate the best possible RTK solution. The 'master auxiliary concept, gives the rover the flexibility to perform either a simple interpolation of the network corrections like FKP, or a more rigorous calculation (for example calculate multiple baselines from the auxiliary reference stations). This means the rover can monitor the RTK solution and change its calculation on-the-fly to optimize the RTK solution. The rover has the possibility to adapt to the prevailing atmospheric conditions by using an appropriate number of reference stations. The MAC corrections allow the rover to measure a baseline to the master station - a real reference station (Brown et al., 2006). This article gives a detailed information on the Turkish RTK CORS Network, CORS-TR Network, later changed its name to TUSAGAAktif Network and its infrastructure. TUSAGA-Aktif Network has been established by Istanbul Kultur University in association with the General Directorate of Land Registration and Cadastre of Turkey and the General Command of Mapping of Turkey and sponsored by the Turkish Scientific and Technical Research Agency (TUBITAK). As with all RTK CORS networks established all around the world, the TUSAGA-Aktif (CORS-TR) networks aims to determine positions fast, economically and reliably with $\mathrm{cm}$ accuracy within minutes, even seconds. However, TUSAGA-Aktif also targets to provide a means to model the atmosphere (troposphere and ionosphere), to predict weather (Roberts et al., 2005; Musa et al., 2005) and to monitor plate tectonics with mmlevel accuracy leading to improvement of earthquake prediction and early warning systems (Brownjohn et al., 2004) and to determine datum transformation parameters between the old system ED50 (European Datum-1950) and ITRF97 (NADCON, 2004; Kempe et al., 2006).

\section{PLANNING AND ESTABLISHING TUSAGA-AKTIF (CORS-TR) NETWORK}

A comprehensive prototype test was carried out in Turkey in the Marmara region (roughly $300 \times 150 \mathrm{~km}$ ) in order to optimize the network design, to test different RTK techniques, and to market the GNSS receivers and control center software packages. As far as the network-base RTK CORS is concerned, this is probably one of the most comprehensive prototype tests in the world (Eren et al., 2009). After conducting the prototype test, it is decided, accounting for geographical conditions of Turkey, that reference stations are: a) to be established in city centers in order to meet intense user 


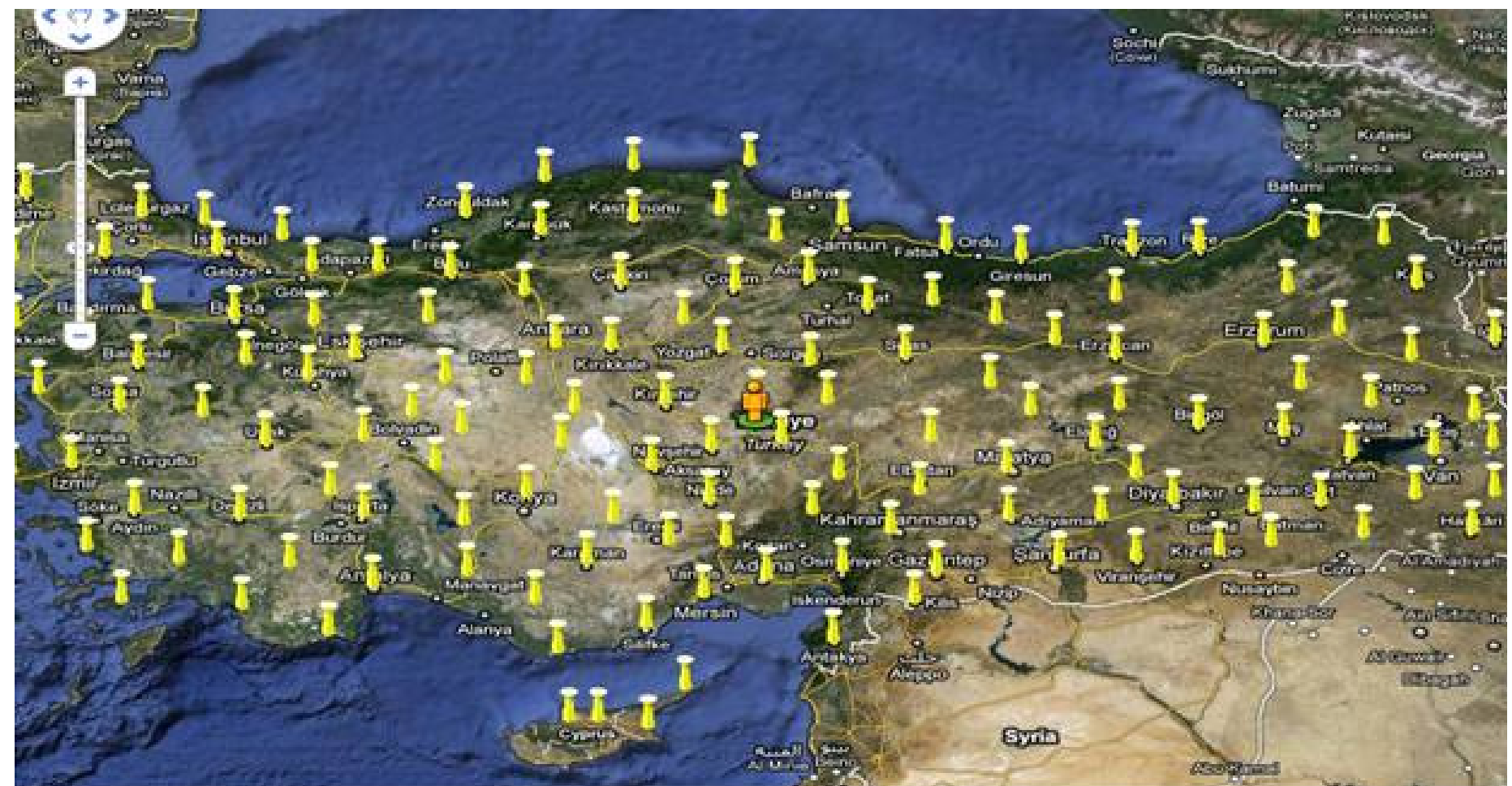

Figure 1. Locations of TUSAGA-Aktif reference stations.

demands and; b) to be on rigid grounds; c) easily accessible for logistic purposes; d) close to energy and communication facilities; e) to be situated in a way that plate tectonics are suitable to monitor and; f) to be apart less than $100 \mathrm{~km}$ (Eren et al., 2009). According to these criteria, a total of 147 reference station locations are determined (Figure 1). All the TUSAGA-Aktif reference stations are named in accordance with IGS regulations having only four characters. Table 1 lists all the station names and locations including the four in Northern Cyprus. The types of monumentation of all 147 reference stations are decided upon ground and regional conditions. Concrete pillar are chosen for rigid ground stations while galvanized steel pillars are constructed for roof tops and roof terraces. However, the heights of pillar change in terms of where they are put up. 86 of them are $2 \mathrm{~m}$ tall concrete pillars, including the ground pillars (Figure 2) while 58 pillars on roof terraces are $3 \mathrm{~m}$ (Figure 3 ) and only 3 of them on roof tops is $4 \mathrm{~m}$ galvanized steel pillars (Figure 4 ).

\section{CONTROL CENTERS}

Two control stations (master and auxiliary) are established both in the capital city Ankara. Master control station is situated in the Photogrammetry and Geodesy Administration of the General Directorate of Land Registration and Cadastre of Turkey and the Auxiliary Control Station in headquarters of the General Command of Mapping of Turkey (Figure 5). All the data from TUSAGA-Aktif reference stations are automatically sent via internet to these control centers in which the network computations and positioning corrections are carried out and send them to users in the field. Control centers have a robust central software as well as servers. This software carries out these functions:

i) Connecting all reference stations and transferring observations,

ii) Computing coordinates of reference stations, iii) Modeling errors, computing corrections and broadcasting to rover stations (users),

iv) RTK services,

v) Web services,

vi) Monitoring rovers,

vii) Storing all the data,

Table 2 lists all the hardware and software contents of both Master and Auxiliary Control Stations which both have a capability of computing and sending real time kinematic GPS corrections. The software for control stations is provided by Trimble VRS SW and originally designed for 250 NetR5 reference stations and consists of GPSNet, RTKNet, webserver, rover integrity, coordinate monitor and data storage modules. It is capable of computing corrections for ionosphere, troposphere, multipath and orbit, and also can broadcast positional correction computed using FKP, VRS and MAC techniques. For the communication between the control center and rovers RTCM 3.0 and higher protocols are used and thus GSM (cellular phones), NTRIP over GPRS/EDGE and radio links are utilized. NTRIP is a protocol for streaming global navigation satellite system (GNSS) data over the Internet. Based on the hyper text transfer protocol HTTP/1.1. NTRIP began as an RTCM standard designed for disseminating differential correction data (for example, in the RTCM-104 format) or other kinds of GNSS streaming data to stationary or mobile users over the Internet, allowing simultaneous PC, laptop, PDA or receiver connections to a broadcasting host. NTRIP is designed to be an open nonproprietary protocol and has gained word-wide recognition as a useful means of transporting GNSS data. Wireless internet services and Mobile IP Networks like global system for mobile communications (GSM), general packet radio service (GPRS), enhanced data rate for global evolution (EDGE) or universal mobile telephone system (UMTS) are all quite capable of carrying NTRIP streams. The TUSAGA-Aktif (CORS-TR) network equipped with NetR5 reference stations and control centers provides RTK GPS 
Table 1. Station names and their locations.

\begin{tabular}{|c|c|c|c|c|c|c|c|c|c|c|c|}
\hline No & Station name & Province & County & No & Station name & Province & County & No & Station name & Province & County \\
\hline 1 & ADAN & Adana & Yüregir & 51 & ERZR & Erzurum & Merkez & 101 & MIDY & Mardin & Midyat \\
\hline 2 & ADIY & Adiyaman & Merkez & 52 & ESKS & Eskisehir & Merkez & 102 & MUGL & Mugla & Merkez \\
\hline 3 & AFYN & A.Karahisar & Merkez & 53 & DINA & Afyon & Dinar & 103 & MURA & Van & Muradiye \\
\hline 4 & AGRD & Agri & Merkez & 54 & FASA & Ordu & Fatsa & 104 & MUUS & Mus & Merkez \\
\hline 5 & AKDG & Yozgat & Akdagmadeni & 55 & FEEK & Adana & Feke & 105 & NAHA & Ankara & Nallihan \\
\hline 6 & AKSI & Antalya & Akseki & 56 & FETH & Mugla & Fethiye & 106 & NEVS & Nevsehir & Merkez \\
\hline 7 & AKHR & Konya & Aksehir & 57 & FINI & Antalya & Finike & 107 & NIGD & Nigde & Merkez \\
\hline 8 & AKSR & Aksaray & Merkez & 58 & GEME & Sivas & Gemerek & 108 & ONIY & Osmaniye & Merkez \\
\hline 9 & AMAS & Amasya & Merkez & 59 & GIRS & Giresun & Merkez & 109 & OZAL & Van & Özalp \\
\hline 10 & ANMU & Içel & Anamur & 60 & GUMU & Gümüshane & Merkez & 110 & POZA & Adana & Pozanti \\
\hline 11 & ANRK & Ankara & Merkez & 61 & GURU & Sivas & Gürün & 111 & RDIY & Tokat & Resadiye \\
\hline 12 & ANTL & Antalya & Merkez & 62 & GYUR & KKTC & Güzelyurt & 112 & RHIY & Erzincan & Refahiye \\
\hline 13 & ANTE & Gaziantep & Sehitkamil & 63 & HAKK & Hakkari & Merkez & 113 & RZE1 & Rize & Merkez \\
\hline 14 & ARPK & Malatya & Arapkir & 64 & HALP & Konya & Halkapinar & 114 & SALH & Manisa & Salihli \\
\hline 15 & ARDH & Ardahan & Merkez & 65 & HARC & Bursa & Harmancik & 115 & SAMN & Samsun & Merkez \\
\hline 16 & ARTV & Artvin & Merkez & 66 & HATA & Hatay & Antakya & 116 & SARY & Tekirdag & Saray \\
\hline 17 & AYD1 & Aydin & Merkez & 67 & HYMN & Ankara & Haymana & 117 & SARV & Karaman & Sariveliler \\
\hline 18 & AYVL & Balikesir & Ayvalik & 68 & HEND & Sakarya & Hendek & 118 & SEND & Hakkari & Semdinli \\
\hline 19 & BALK & Balikesir & Merkez & 69 & HINI & Erzurum & Hinis & 119 & SIHI & Eskisehir & Sivrihisar \\
\hline 20 & BAND & Balikesir & Bandirma & 70 & HORS & Erzurum & Horasan & 120 & SIRT & Siirt & Merkez \\
\hline 21 & BTMN & Batman & Merkez & 71 & IGIR & Igdir & Merkez & 121 & SLEE & Istanbul & Sile \\
\hline 22 & BAYB & Bayburt & Merkez & 72 & INEB & Kastamonu & Inebolu & 122 & SILF & Mersin & Silifke \\
\hline 23 & BEYS & Konya & Beysehir & 73 & ISPA & Isparta & Merkez & 123 & SINP & Sinop & Merkez \\
\hline 24 & BILE & Bilecik & Merkez & 74 & ISTN & Istanbul & Bakirköy & 124 & SIRN & Sirnak & Merkez \\
\hline 25 & BING & Bingöl & Merkez & 75 & IZMI & Izmir & Konak & 125 & SIVS & Sivas & Merkez \\
\hline 26 & BOGZ & Yozgat & Bogazliyan & 76 & IZMT & Kocaeli & Izmit & 126 & SIVE & Sanliurfa & Siverek \\
\hline 27 & BOLU & Bolu & Merkez & 77 & KRBK & Safranbolu & Merkez & 127 & SUNL & Çorum & Sungurlu \\
\hline 28 & BOYT & Sinop & Boyabat & 78 & KAMN & Karaman & Merkez & 128 & SURF & Sanliurfa & Merkez \\
\hline 29 & BURS & Bursa & Osmaniye & 79 & KAPN & Konya & Karapinar & 129 & SSEH & Sivas & Susehri \\
\hline 30 & CMLD & Ankara & Çamlidere & 80 & KARB & Istanbul & Karaburun & 130 & TVAN & Bitlis & Tatvan \\
\hline 31 & CANA & Çanakkale & Merkez & 81 & $\mathrm{KRS} 1$ & Kars & Merkez & 131 & TEKR & Tekirdag & Merkez \\
\hline 32 & CANK & Çankiri & Merkez & 82 & KSTM & Kastamaonu & Merkez & 132 & TOKA & Tokat & Merkez \\
\hline 33 & CATK & Van & Çatak & 83 & KAYS & Kayseri & Melikgazi & 133 & TRBN & Trabzon & Merkez \\
\hline 34 & CAVD & Burdur & Cavdir & 84 & KESA & Edirne & Kesan & 134 & TUFA & Adana & Tufanbeyli \\
\hline 35 & CESM & Izmir & Çesme & 85 & KLIS & Kilis & Merkez & 135 & TNCE & Tunceli & Merkez \\
\hline
\end{tabular}


Table 1. Contd.

\begin{tabular}{|c|c|c|c|c|c|c|c|c|c|c|c|}
\hline 36 & $\mathrm{CIHA}$ & Konya & Cihanbeyli & 86 & $\mathrm{KIRL}$ & Kirklareli & Merkez & 136 & UDER & Erzurum & Uzundere \\
\hline 37 & CORU & Çorum & Merkez & 87 & $\mathrm{KIRI}$ & Kirikkale & Merkez & 137 & USAK & Usak & Merkez \\
\hline 38 & DATC & Mugla & Datça & 88 & KIKA & Manisa & Kirkagaç & 138 & VAAN & Van & Merkez \\
\hline 39 & DEIR & Manisa & Demirci & 89 & KIRS & Kirsehir & Merkez & 139 & VEZI & Samsun & Veziköprü \\
\hline 40 & DENI & Denizli & Merkez & 90 & KNYA & Konya & Selçuklu & 140 & VIRA & Sanliurfa & Viransehir \\
\hline 41 & DIDI & Aydin & Didim & 91 & KLUU & Konya & Kulu & 141 & BASK & Van & Baskale \\
\hline 42 & DIPK & KKTC & Dipkarpaz & 92 & KURU & Bartin & Kurucasile & 142 & YENC & Çanakkale & Yenice \\
\hline 43 & DIVR & Sivas & Divrigi & 93 & KUTA & Kütahya & Merkez & 143 & YOZT & Yozgat & Merkez \\
\hline 44 & DIYB & Diyarbakir & Merkez & 94 & LEFK & KKTC & Lefkosa & 144 & YUNK & Konya & Yunak \\
\hline 45 & EDIR & Edirne & Merkez & 95 & MGOS & KKTC & Magosa & 145 & ZONG & Zonguldak & Merkez \\
\hline 46 & EKIZ & K.Maras & Ekinözü & 96 & MALY & Malatya & Merkez & 146 & AHGK & Ankara & Merkez \\
\hline 47 & ELAZ & Elazig & Merkez & 97 & MALZ & Mus & Malazgirt & & & & \\
\hline 48 & EMIR & Afyon & Emirdag & 98 & MARA & K.Maras & Merkez & & & & \\
\hline 49 & ERGN & Diyarbakir & Ergani & 99 & MARD & Mardin & Merkez & & & & \\
\hline 50 & ERZI & Erzincan & Merkez & 100 & MRSI & Mersin & Merkez & & & & \\
\hline
\end{tabular}

positioning $24 \mathrm{~h}$ a day all over Turkey and the North Cyprus. Table 2 tabulates the contents and amounts of both 'master and auxiliary' (shown as Mstr and Aux in column headings) control stations. All the reference stations are geographically divided into four regions and thus four GPSnet servers (plus 4 auxliary servers) in the 'master control center' (Figure 6). Each server is backed with an auxiliary server which automatically takes over the work in case of any failure in the main server. The control centers collect receiver independent exchange (RINEX) format data from the reference stations in $1 \mathrm{~s}$ interval for an hour and $30 \mathrm{~s}$ intervals for $24 \mathrm{~h}$, and precise ephemerid data are automatically uploaded by the system.

The 'master and auxiliary control centers' broadcast the coordinate correction using VRS CMR+, VRS RTCM 3.1, SAPOS FKP 2.3, RTCM3Net (MAC) and DGPS techniques. A separate webrouter transfers all the data from the reference stations to the main GPSnet servers and auxiliary webrouter in real time. A secondary webrouter is designed to step in as an auxiliary in case of any failure. All the correction broadcasting is maintained through NTRIP Caster and CORSIZ program developed by GRAFTEK INC. manages the users and records all the user information. Furthermore, user or rovers are monitored by the software called CORSTAK implemented by GRAFTEK INC. over Google Earth ${ }^{\mathrm{TM}}$ in real time (Figure 7). For static GPS data, a webserver software is run on webrouter and users can obtain RINEX data for observation time and time interval for any reference station. A TB hotswap RAID (plus an auxiliary) is formed on a NAS (network attached storage) server, storing RINEX data (in Hatanaka format), reports, log files and hourly registry back-ups from all the servers.

\section{REFERENCE STATIONS}

A total of 147 TUSAGA Aktif reference stations are established in the field with baseline separation of 70 to $100 \mathrm{~km}$ as deduced from the prototype test (Figure 8). Fo every reference station, a GPS cabinet is specially designed for TUSAGA Aktif project. These cabinets have glass doors when used indoors or steel doors on outside use. They are designed to work independent of mains electricity problems, fed on $12 \mathrm{~V}$ DC batteries; in other words, main grid electricity is only used for charging these batteries which can go on working for $48 \mathrm{~h}$ without any electricity charging. Naturally different battery amperes had to be applied depending on the general temperature values of the region where reference stations are (Figure 9a). Each cabinet contains: a) 1 Victron Bluepower charger/power unit, b) 1 Trimble NetR5 GNSS receiver, c) 1 Sarian DR6410 Router/switch (ADSL/EDGE), d) 1 LVD voltage protection detector, e) lightning arrester for telephone and antenna lines, and f) fuses and electronic cabling assembly (Figure 9b). The antennas used on al the reference stations are Trimble Zephyr Geodetic II ${ }^{\mathrm{TM}}$ and Radome is also installed on antennas where snow load is expected. All the antennas are placed on pillars leveled by special tripods with fixed height, yielding an extremely 


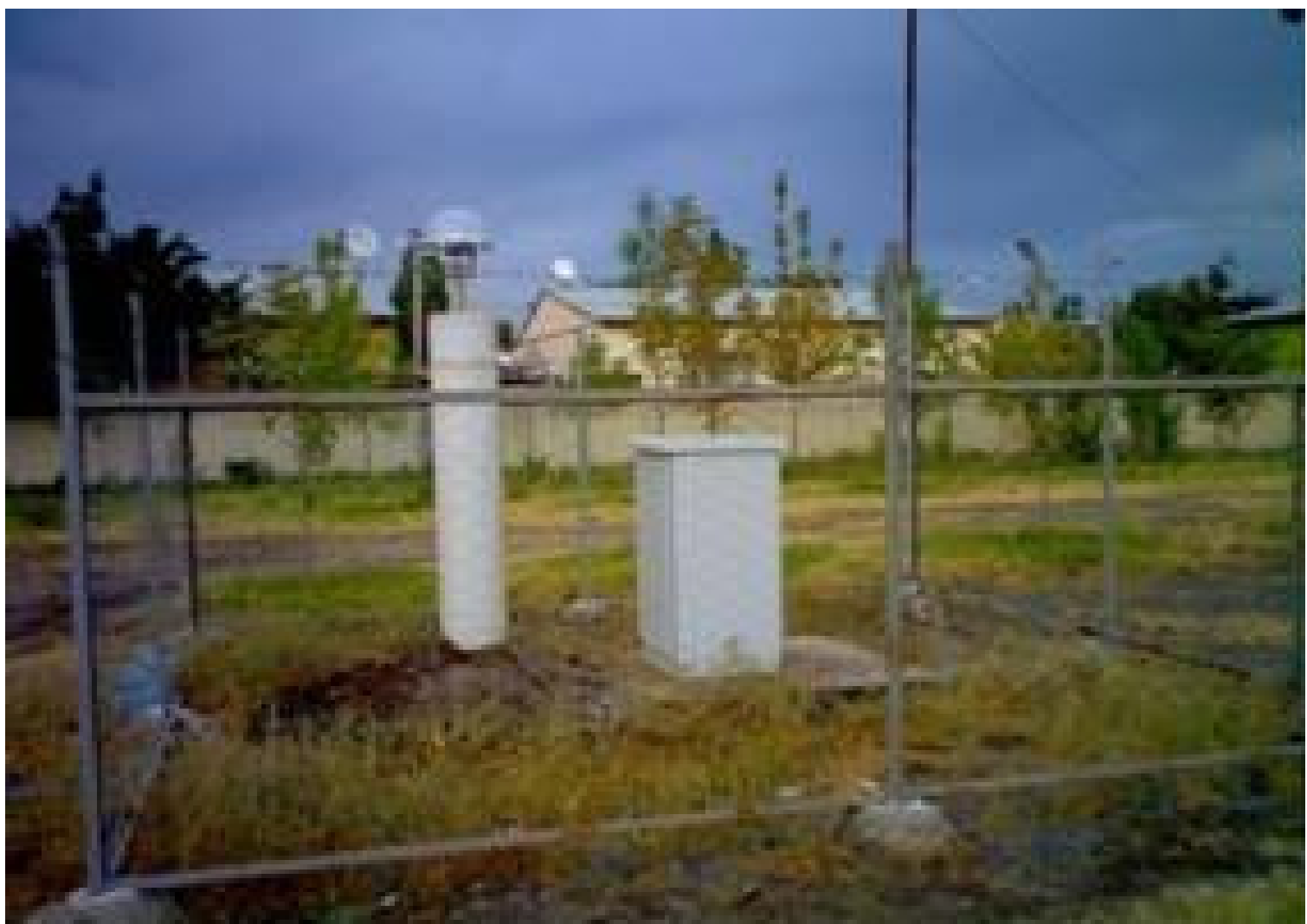

Figure 2. Concrete pillar (2 m).

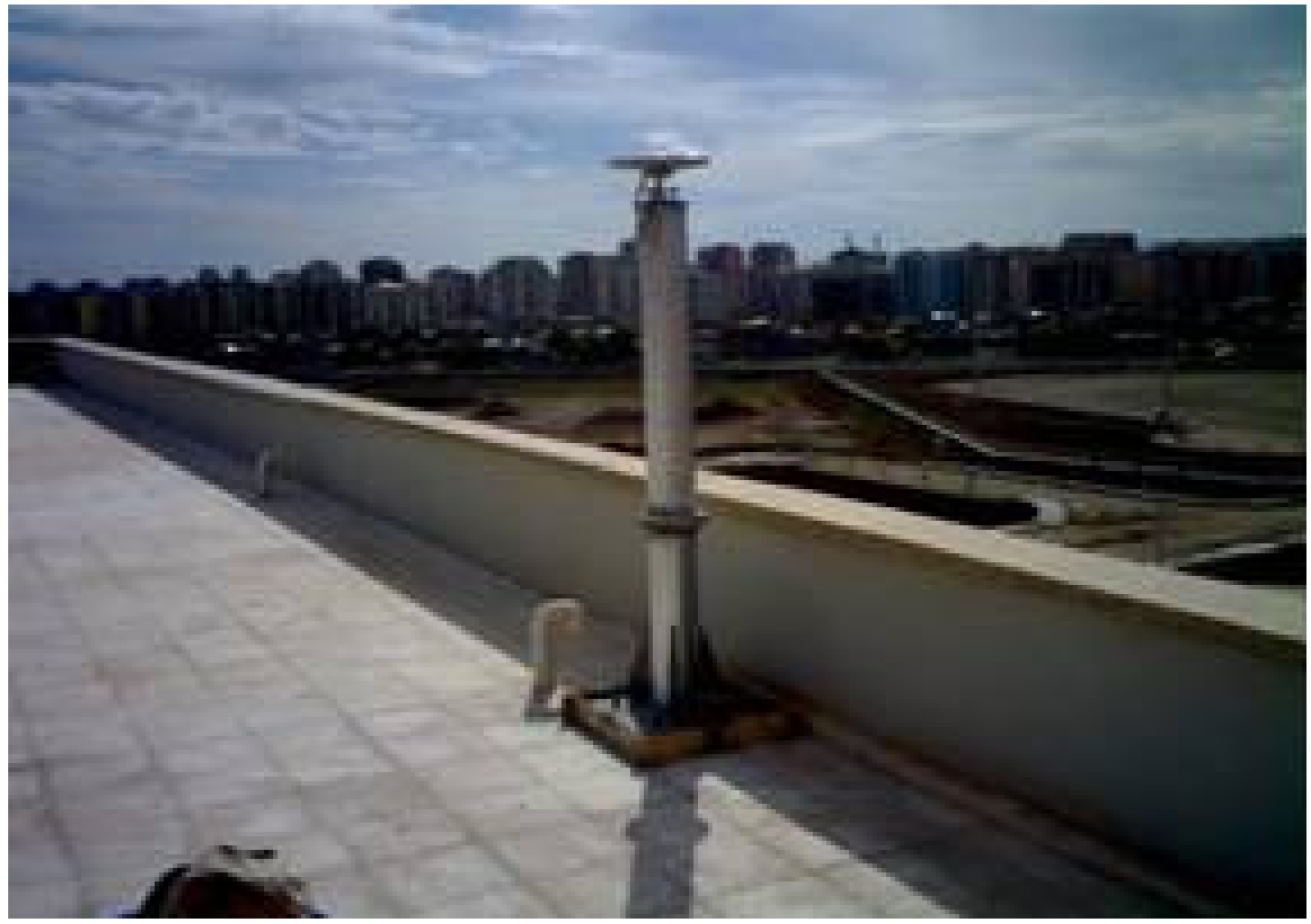

Figure 3. Galvanized steel pillar (3 m). 


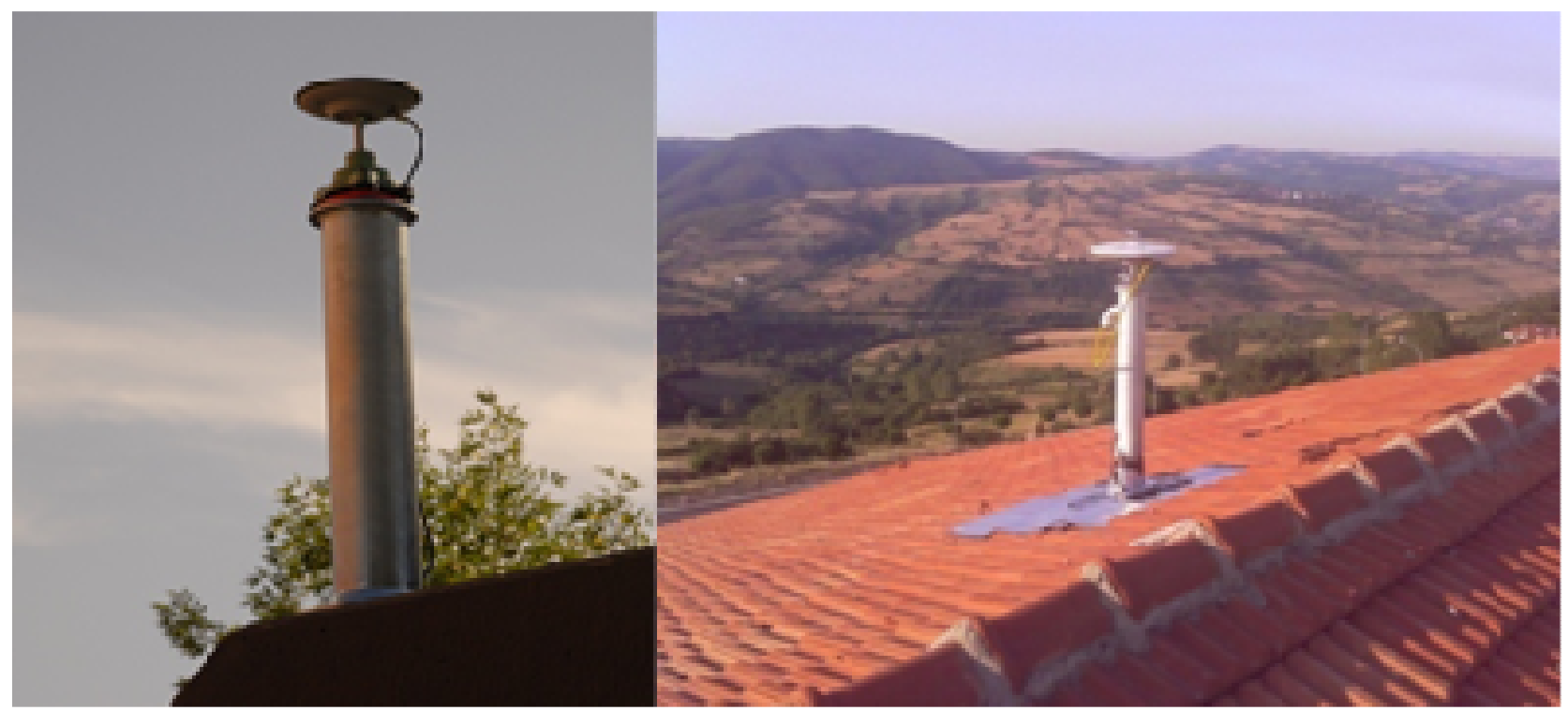

Figure 4. Galvanized steel pillar (4 $\mathrm{m}$ from the base of roof).

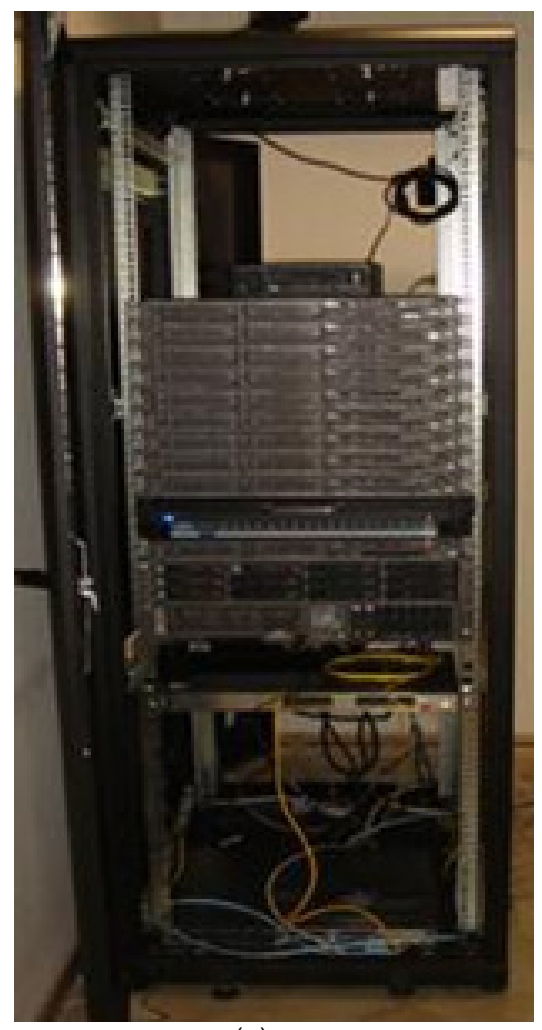

(a)

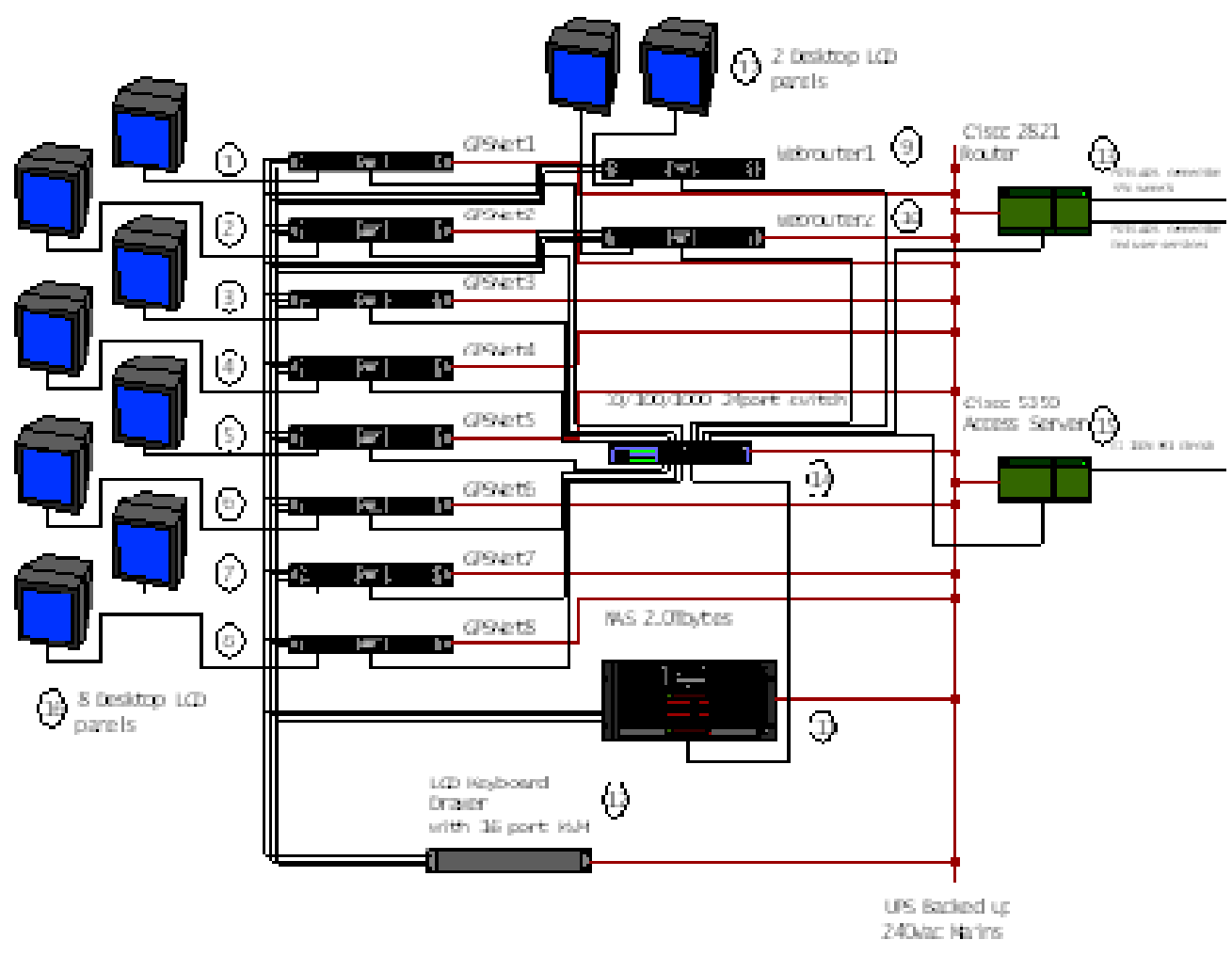

(b)

Figure 5. Master control station and its schematic representation.

precise and standard antenna height. All the stations possess static IPs and VPN tunnel (internal IP) communication via CISCO routers. However, in case of any router problem, the system is planned to also work with static IPs through a standard regular router.

\section{COMMUNICATION}

The communication between the control centers and stations are maintained by duplex ADSL and GPRS/EDGE. For this purpose, 
Table 2. Contents of master and auxiliary control stations.

\section{Contents}

DL140G3 Dual-Core X5110 3.00 GHZ-1 x 4 mb 1 gb 80 gb SATA 1 U Rack; Windows 2003 Server.

DL140G3 Dual-Core 2x X5110 3.00 GHZ-1 x 4 MB 1 GB 80 GB SATA 1 U Rack; Windows 2003 Server; 2 x 1 GB FBD.

NAS HP DL380 2TB SATA Storage Server; Dual-Core; 1 GB DIMM; 2 x 1 GB FBD.

Storage works backup unit with smart array.

17" LCD TFT flat panel monitor.

CISCO 2811 Router with VPN encryption; 2x DSL interface.

24-port unmanaged switch.

19" 16-port KWM switch.

19" 42U Server Max cabin with FAN and Thermostat module.

19" Rack console with 17" TFT display, keyboard, mouse, touchpad.

HP A4 laser printer

Trimble VRS SW (including GPSNet, RTKNet, webserver, Rover integrity, coordinate monitor and data storage) for 150 GNSS stations/nodes. Microsoft Office (including MS Access).

Working table.

VNCe SW.

IPCluster SW.

\begin{tabular}{cc} 
Mstr & Aux \\
\hline 8 & 4 \\
2 & 1 \\
1 & 1 \\
1 & 1 \\
10 & 5 \\
1 & 1 \\
1 & 1 \\
1 & 1 \\
1 & 1 \\
1 & 1 \\
1 & 1 \\
1 & 1 \\
1 & 1 \\
3 & 3 \\
11 & 5 \\
2 & 1
\end{tabular}

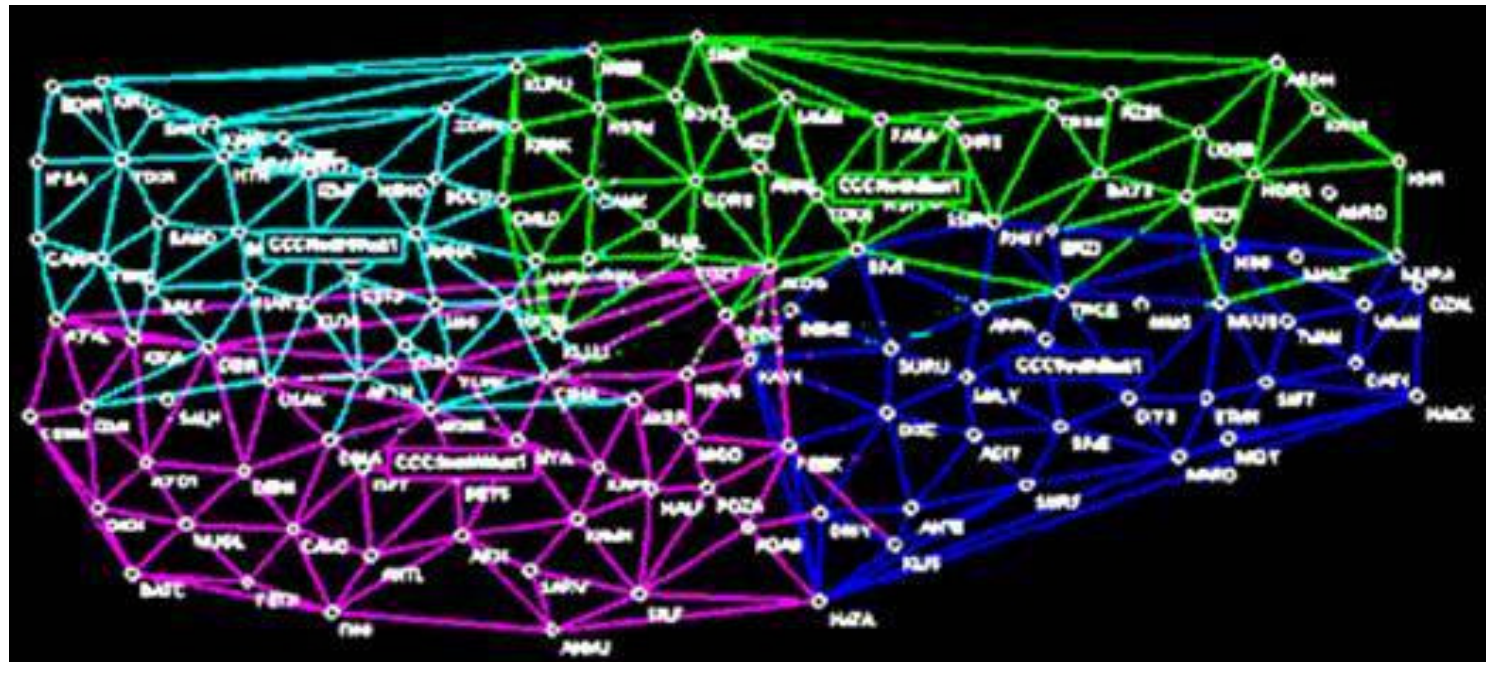

Figure 6. Reference stations and their server regions. 

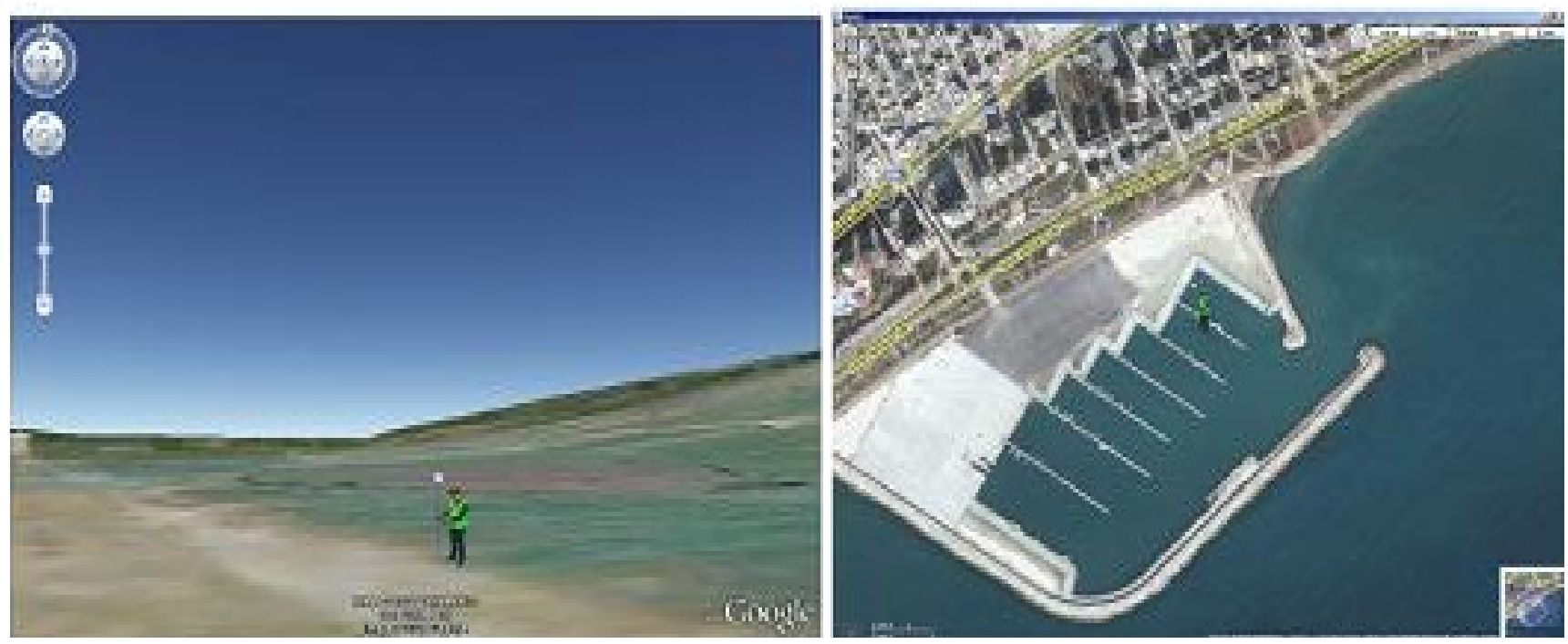

Figure 7. Monitoring users in real time.

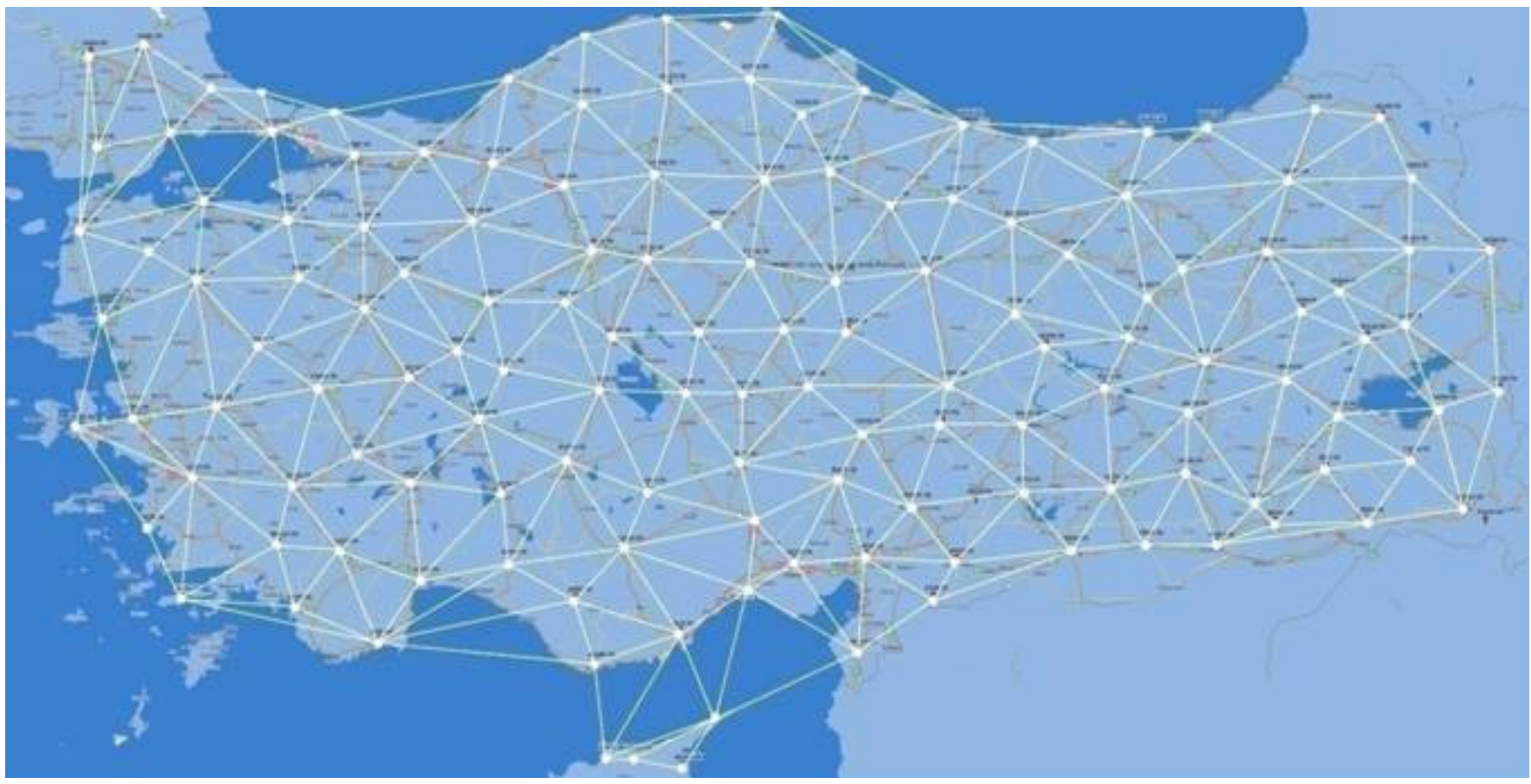

Figure 8. The network of TUSAGA Aktif reference stations.

the 'master control center' has 20 Mbit and the 'auxiliary' 10 Mbit metro internet connection. Moreover it is possible to connect each reference station via GPRS/EDGE. After carrying out intensive test, it is found out that approximately 15 stations do not high quality line connections as the other. The metro connections in the control centers experience some data loss and slowing down especially during the peak times; however, this does not affect the RTK GPS tasks badly because the missing RINEX data are automatically replaced by the back-up ones kept in the centers. The data send by each reference stations are about 700 byte/s and the total amount data from the stations to the control centers is approximately 1.2
Mbit; concurrently daily RINEX data recorded at $1 \mathrm{~s}$ interval $20 \mathrm{~Gb}$ while RINEX data (in Hatanaka format) at $30 \mathrm{~s}$ interval is $239 \mathrm{Mb}$.

\section{RESULTS AND DISCUSSION OF TUSAGA-AKTIF NETWORK TEST}

The precise coordinates of TUSAGA-Aktif reference stations were calculated in ITRF 2005 datum and at the observation epoch utilizing two-weeks data of all the 


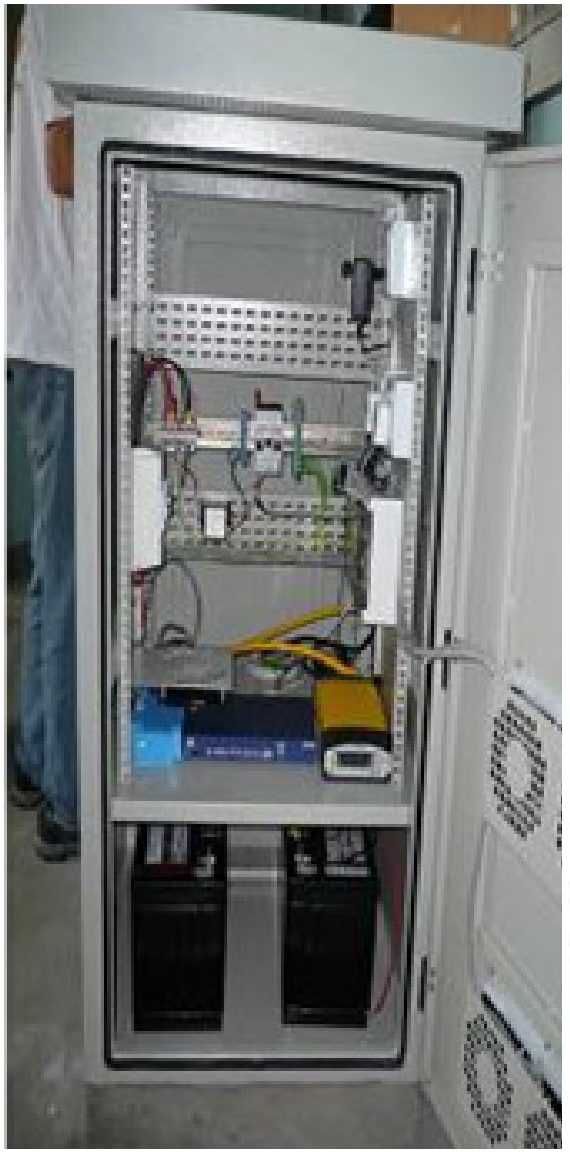

(a)

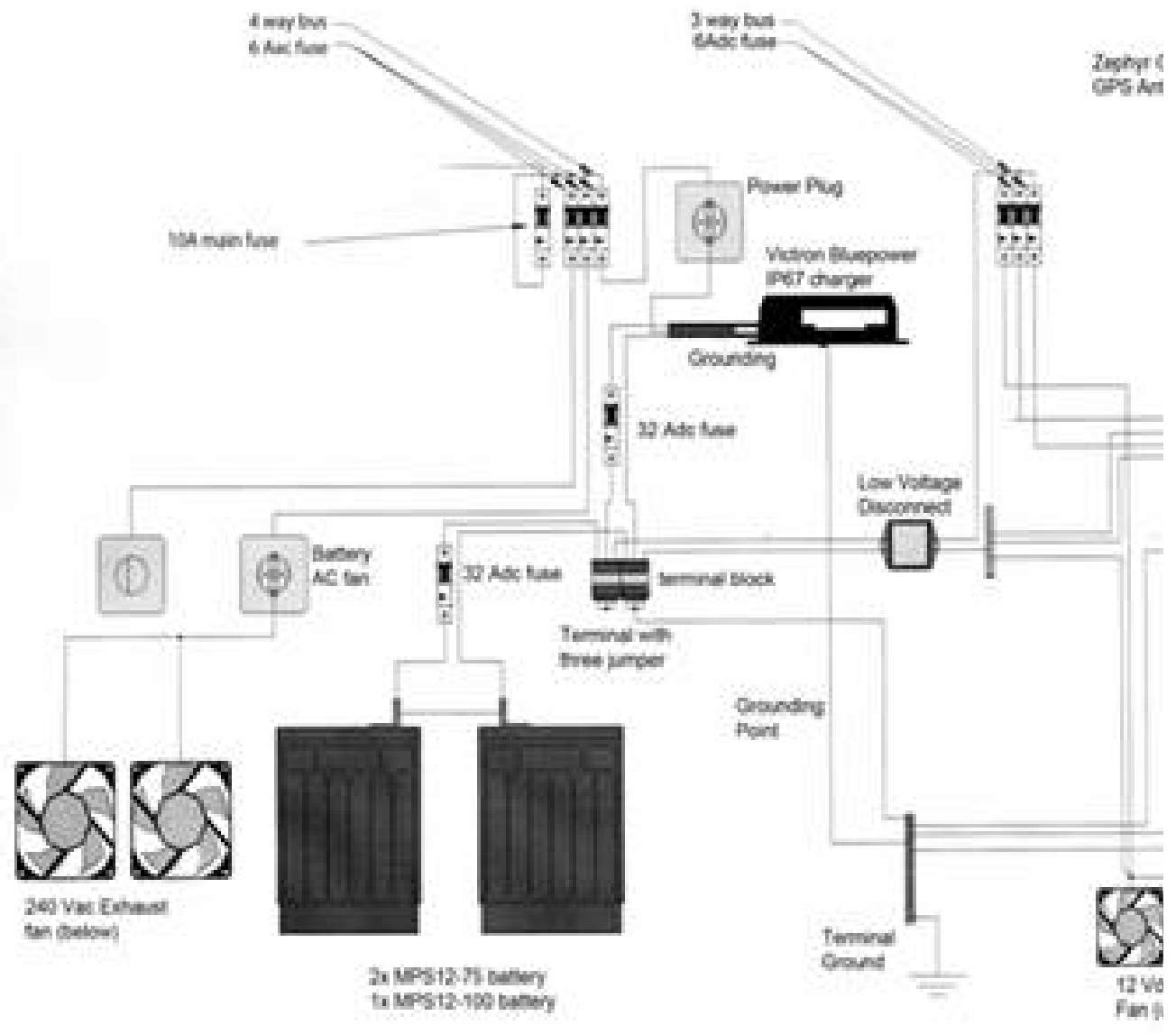

(b)

Figure 9. Reference station cabinet (a) and schematic representation of cabinet components (b).

Table 3. Statistics of the measurements.

\begin{tabular}{lccc}
\hline & Northing $\mathbf{~ m})$ & Easting $(\mathbf{m})$ & Height (m) \\
\hline No. of measurements & 808 & 808 & 808 \\
Smallest difference & -0.4990 & -0.3280 & -0.3077 \\
Largest difference & 0.2178 & 0.3092 & 0.2687 \\
Average & -0.0153 & -0.0103 & -0.0266 \\
Standard deviation & 0.042542438 & 0.03816926 & 0.090720529 \\
\hline
\end{tabular}

reference stations together with the IGS stations such as GRAS, GRAZ, KIT3, KOSG, MATE, NICO, NOT1, NSSP, ONSA, SOFI, VILL, WTZR and ZECK. The computations were carried out by using Bernese 5.0 and GAMIT software packages together with precise ephemeris. As of January 31, 2010, all the reference stations are completed except 1 stations in Northern Cyprus. Although the system is in the test stage, there are over 2000 users benefiting from the system throughout Turkey to determine their precise coordinates by RTK or post processing techniques. They are able to determine their precise coordinates in matters of seconds. For the purpose of testing the system, 808 points with their precisely known ITRF2005.00 coordinates are taken into account because they are homogenously scattered around the country in both urban and rural areas. Table 3 lists all the results obtained from the test. In Table 3 it can be seen that the largest standard deviation, as expected is obtained in the height component while the values of nothing and easting components are comparable. Figure $10 a, b$ and $c$ give error distributions of the measurements in northing, easting and height components. The TUSAGA-Aktif network commenced working in 2009 and the number of users are increasing exponentially. At the beginning of 2010, the daily user number has reach 350 to 370 rover on average and the instantaneous user 


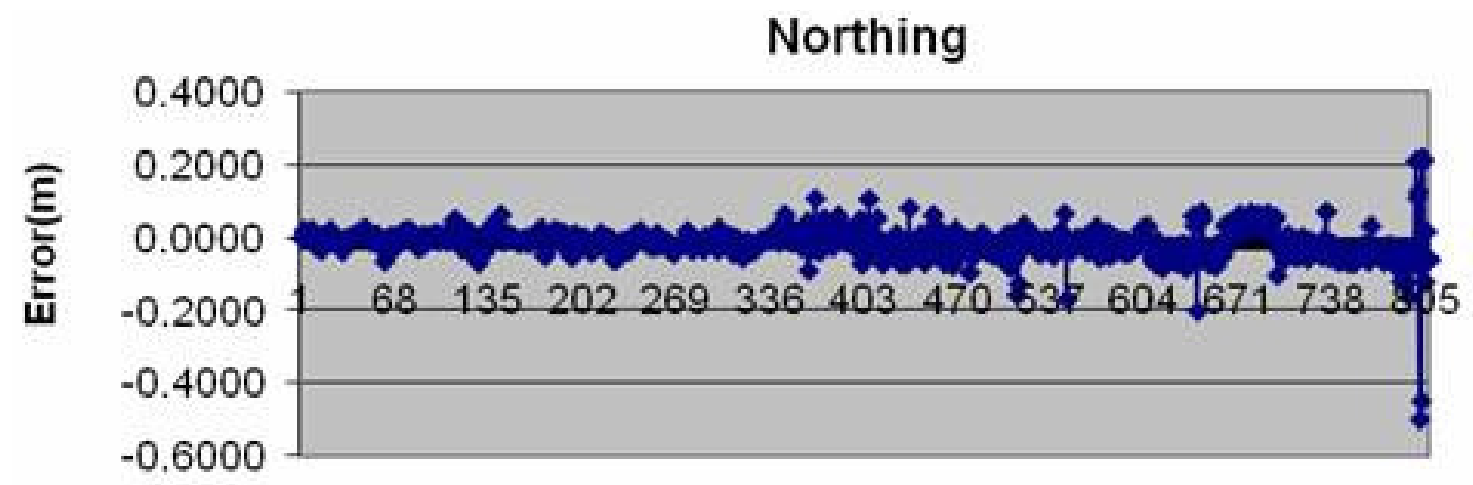

Ground Control Points

Figure 10a. Error distribution in northing component.

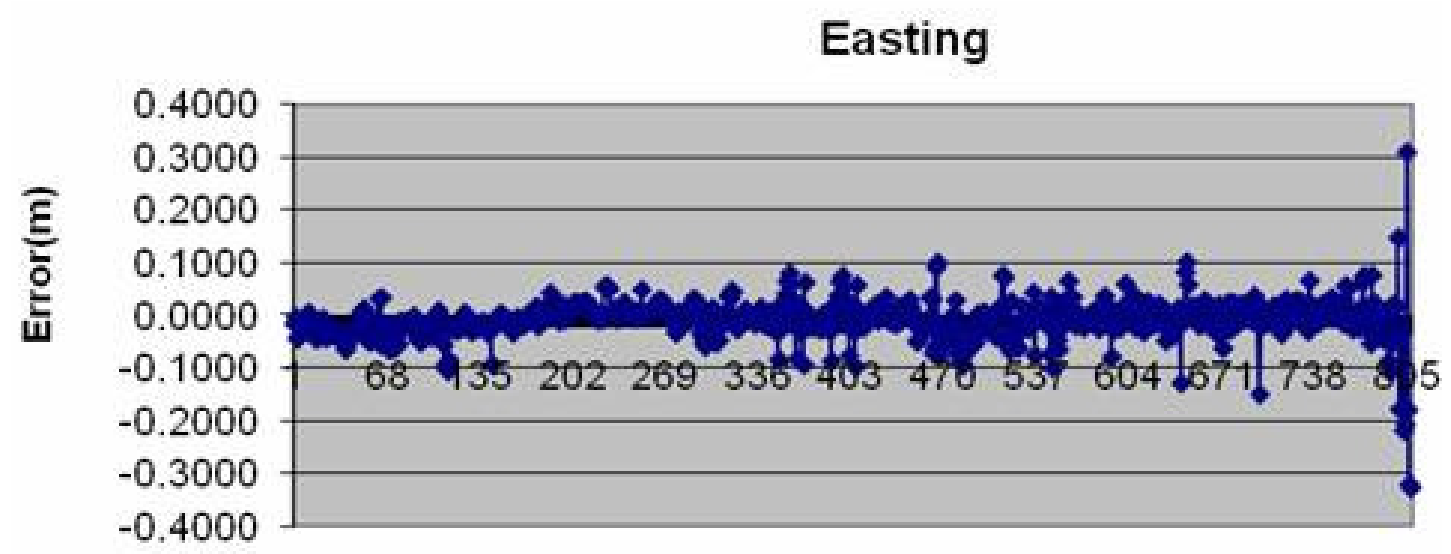

Ground Control Points

Figure 10b. Error distribution in easting component.

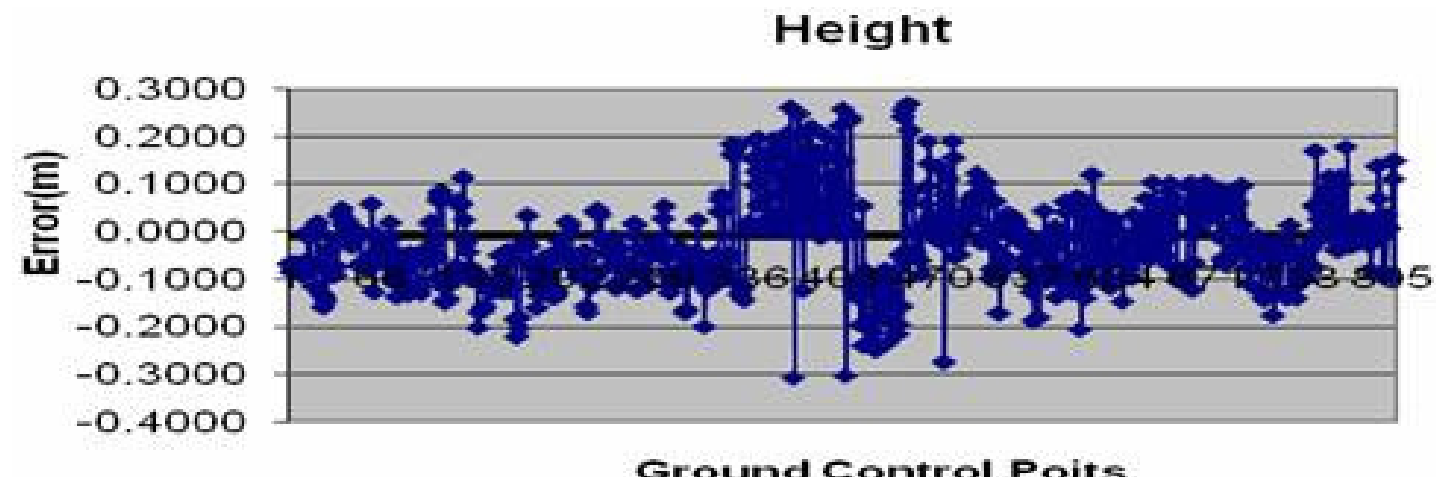

Figure 10c. Error distribution in height component.

number in the range of 100 to 130 , evenly scattered over Turkey in terms of their location. However, the frequency in user is high in the Marmara Region due to intensive industry while low in the mountainous Black sea Region and the Central Anatolia with plains (Figure 11). As for the coordinate correction types are concerned, VRS has the highest preference rate with $46 \%$ and the most favored correction formats are CMR+ and RTCM3.1 (Figure 12). As with all the RTK network around the world, the success in the TUSAGA-Aktif network mainly 


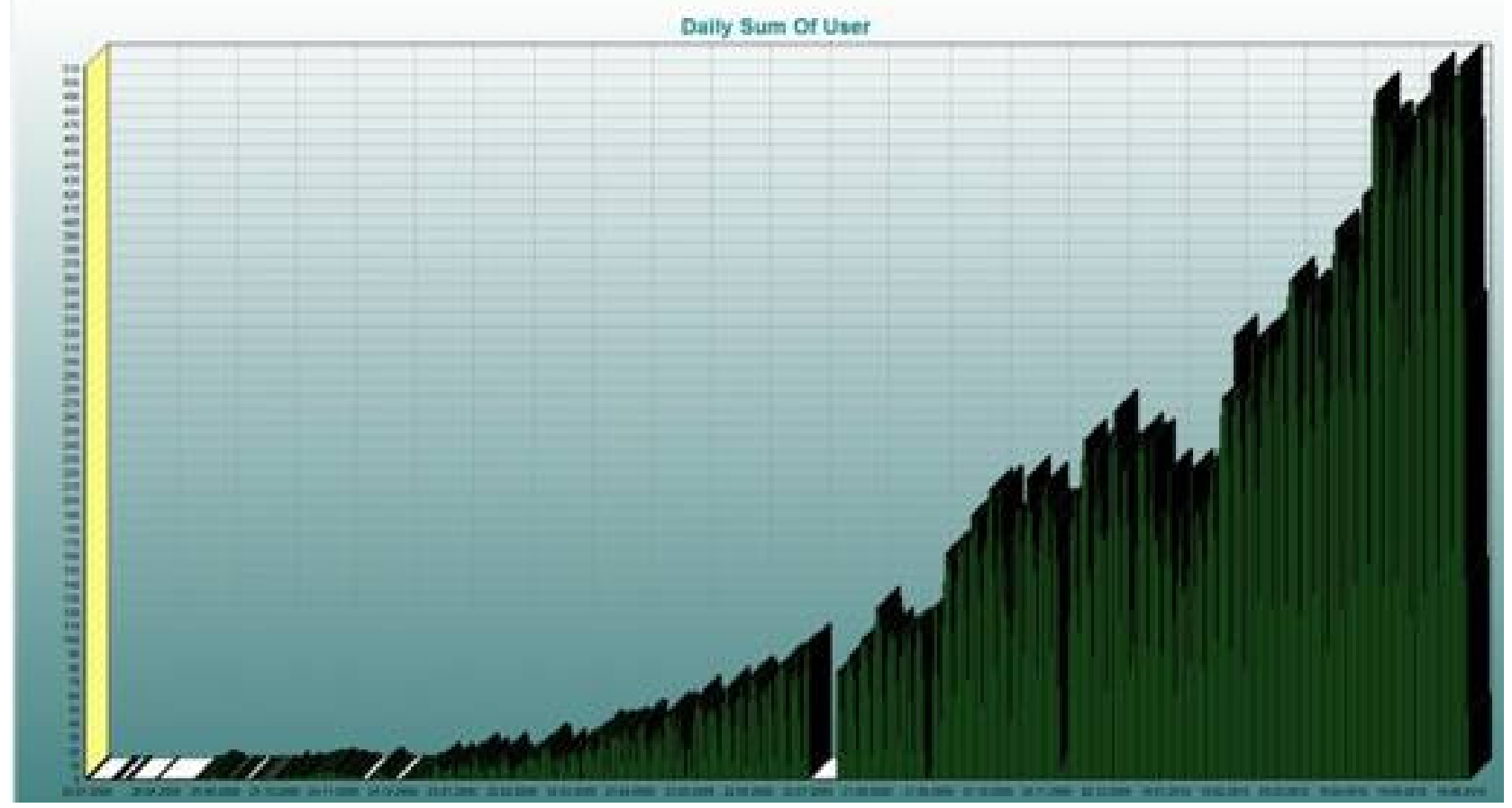

Figure 11. Daily usage from the beginning.

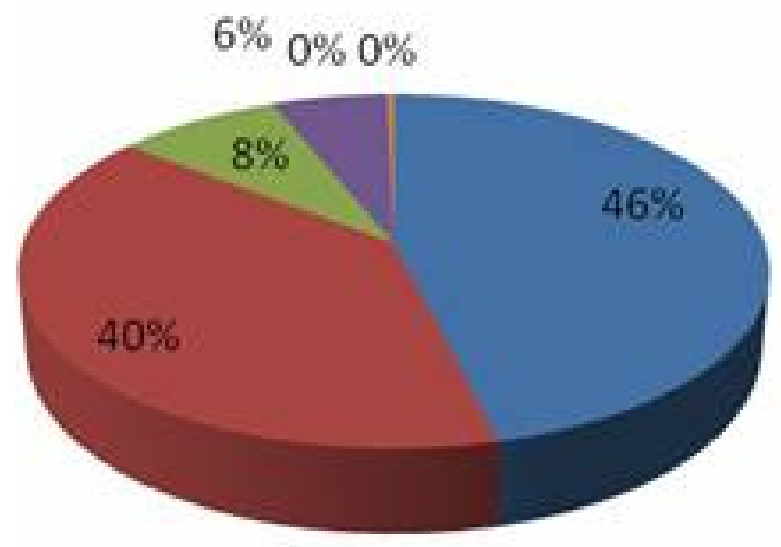

- VRSCMRP

- VRSRTCM 31

플 SAPOS

- RTCM3NET

= DGPSNET

a RTKNETCMRP

Figure 12. Percentage of the coordinate correction formats used.

lies in the quality of the communication between the centers and the reference stations and between the reference stations and users (Landau et al., 2004). In Turkey, the copper is usually made used for ADSL lines except for some big cities, and these lines are very old, unfortunately subject to corrosions. Therefore the places with this kind of infrastructure can experience outages, slowing downs and delays in ADSL communications. Nevertheless the system automatically opens up GPRS/EDGE channel in cases of outages and the user in the field are not aware of these outages.

Despite all this, the troubled areas, which are generally
15 points and daily 5 stations experiencing $1 \mathrm{~h}$ or over ADLS connection problem, are being overcome with the cooperation of Turkish Telekom. One of the great advantages of the TUSAGA-Aktif network is the ability to automatically form a new sub network in that region when a reference station is cut off from the world and the users in the field are not affected by this. The data generated in the network are always studied using coordinate-time series. The evaluation of this fashion revealed that 5 reference stations had multipath effects and cycle slips. Figure 13 demonstrates three graphs for the coordinatetime series of ADAN station, one of the stations with low 
ADAN North Offset $4119210.764 \mathrm{~m}$

rate $(\mathrm{mm} / \mathrm{y})=26.34 \pm 0.71 \mathrm{nrms}=1.27 \mathrm{wrms}=2.5 \mathrm{~mm} \# 208$

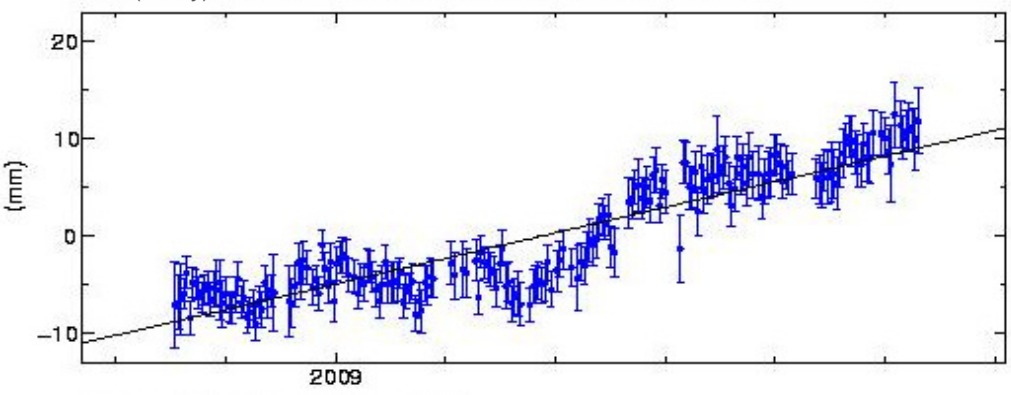

ADAN East Offset $3142010.457 \mathrm{~m}$

rate $(\mathrm{mm} / \mathrm{y})=67.60 \pm 0.73 \mathrm{nrms}=2.72 \mathrm{wrms}=5.5 \mathrm{~mm} \# 208$

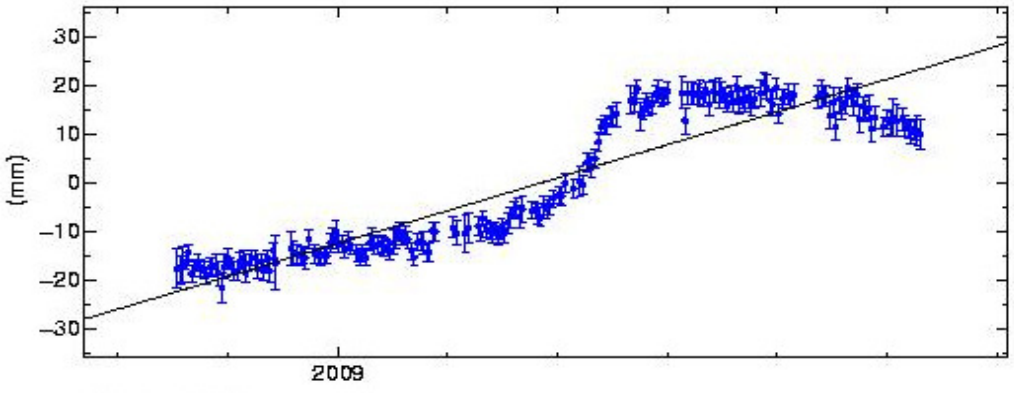

ADAN Up Offset $\quad 60.523 \mathrm{~m}$

rate $(\mathrm{mm} / \mathrm{y})=23.17 \pm 2.66 \mathrm{nrms}=0.64 \mathrm{wrms}=4.8 \mathrm{~mm} \# 208$

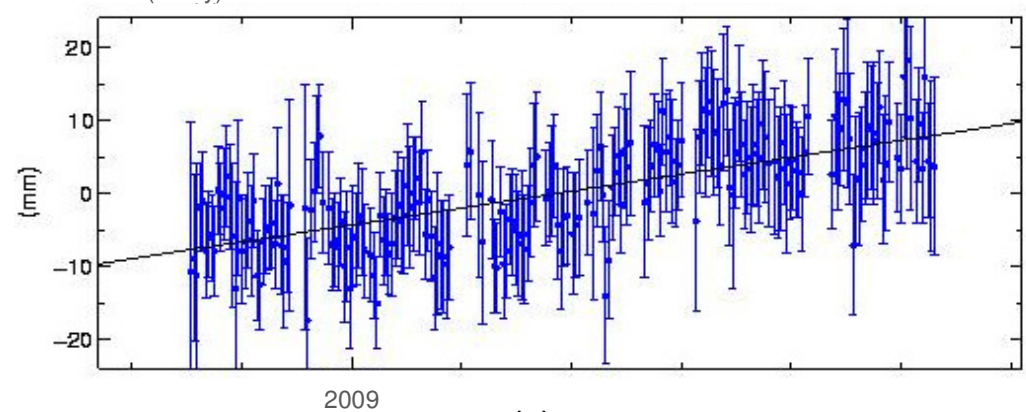

(a)

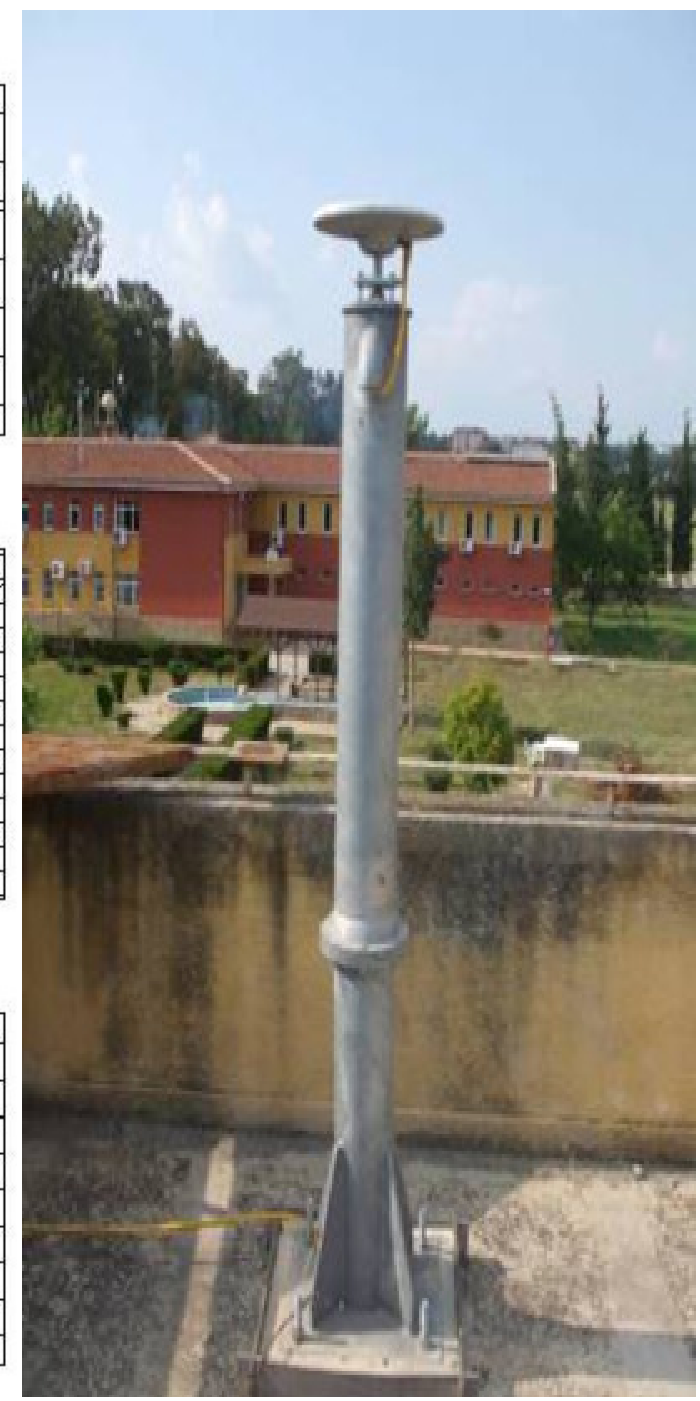

(b)

Figure 13. ADAN station and its coordinate-time series.

performance. Looking closely at the series, one can observe that the northing and easting components show different behaviors than the others. All the stations with low or bad performances are being planned to change their locations.

\section{Conclusion}

The Turkish RTK CORS Network TUSAGA-Aktif has been serving increasing number of users since the beginning of 2009 and the number has reached over 3600 as of April 2011. It made an enormous impact around nationwide 4000 GNSS receivers by enhancing their performance to $50 \%$, and presents a great advantage of establishing a base for all kinds of geographical information systems and technologies.
Nationwide cadastral and geodetic tasks will be carried out fast, economically and reliably without the necessity of local reference points. Furthermore, the velocities of the national geodetic points will be determined on daily basis and tectonic plate movements will be monitored effectively because of the fact that Turkey is on active earthquake bearing faults such as the North Anatolian Faults and South Anatolian Fault. The nationwide cadastre renewal tasks worth 220 million US Dollars has been initiated and the geodetic infrastructural works constitute $20 \%$ of these tasks and is estimated to bring about a saving of 35 million US Dollars which is about the seventh of the cost of establishing all the TUSAGA-Aktif network. In the first year, the network has already compensated the money that went into establishing and running the system. Apart from the countless professional benefits and applications that this kind of system provides, 
the financial benefit alone is worth considering for all developing countries all around the world.

\section{REFERENCES}

Bock Y, Cecil H, Ida M (2002). The California CORS Program. CORS users' forum, national geodetic survey, NOAA/NOS, Silver Spring, Md.

Bray C, Greenway I (2004). The Osi National Network RTK Solution, FIG Working Week 2004, 22-27 May, Athens, Greece.

Brown N, Geisler I, Troyer L (2006). RTK Rover Performance using the Master-Auxiliary Concept, J. Global Pos. Sys., 5: 135-144.

Brownjohn JM, Rizos C, Tan GH, Pan TC (2004). Real-time long-term monitoring and static and dynamic displacements of an office tower, combining RTK GPS and accelerometer data. 1st FIG Int. Symp. on Engineering Surveys for Construction Works \& Structural Engineering.

Cruddace P, Wilson I, Greaves M, Euler HJ, Keenan R, Wübbena G (2002). The Long Road To Establishing A National Network RTK Solution", FIG XXII International Congress, Session no. TS5.6, 19-26 April, Washington, USA.

Evans AG, Swift ER, Cunningham JP, Hill RW, Blewitt G, Yunck TP, Lichten SM, Hatch RR, Malys S, Bossler J (2002), The Global Positioning System Geodesy Odyssey, Navigation, 49: 7-34.

Eren K (2005).The Establishment of Saudi CORS and SGD-2000 Geodetic Network, Ministry of Municipal and Rural Affairs, Saudi Arabia.

Eren K, Uzel T, Gulal E, Yildirim O, Cingoz A (2009). Results from a Comprehensive Global Navigation Satellite System Test in the CORS-TR Network; Case Study. J. Surv. Engrg., 135: 10-18

Grejner-Brzezinska DA, Kashani I, Wielgosz P, Smith DA, Spencer PSJ, Robertson DS, Mader GL (2007). Efficiency and reliability of ambiguity resolution in network-based real-time Kinematic GPS., J. Surv. Eng., 133: 56-65.

Kempe C, Alfredsson A, Engberg LE, Lilje M (2006). Correction model to rectify distorted co-ordinate system. XXIII FIG Congress.

Lachapelle G, Ryan S, Rizos C (2002). Servising the GPS User, chapter 14 in Manual of Geospatial Science and Technology, J. Bossler, J. Jenson, R. McMaster \& C Rizos (eds.), Taylor \& Francis Inc., pp. 201-215.

Landau H, Vollath U, Chen X, Allison T (2004). Benefits of Modernized GPS/Galileo to RTK Positioning Presented at GNSS 2004 The 2004 International Symposium on GNSS/GPS Sydney, Australia 6-8 December 2004

Mekik C (2004). Positioning with Real Time Kinematic GPS Network (Netwrok RTK). Presented in Sypm. on Geodetic Network in Engineering Surveys by Turkish National Geodesy Commission, Karaelmas University., Zonguldak, Turkey, pp. 202-207.

Musa TA, Lim S, Rizos C (2005). Low latitude troposphere: A preliminary study using GPS CORS data in South East Asia. U.S. Institute of Navigation National Tech. Meeting, San Diego, California, January 24-26, pp. 685-693.

NADCON (2004). North American Datum Conversion Utility, NOAA Technical Memorandum NOS NGS-50, USA,

Retscher G (2002). Accuracy Performance of Virtual Reference Station Networks, J. Global Positioning Syst., 1: 40-47.

Rizos C, Yan T, Omar S, Musa T (2003). Implementing network RTK: the SydNET CORS infrastructure. The 6th Internation Symposium on Satellite Navigation Technology Including Mobile Positioning and Location Services, Melborne, Australia, 22-25 July.

Rizos C (2007). "Alternative to current GPS-RTK services and some implications for CORS infrastructure and operations," GPS Solut., 11:(3): 151-158.

Rizos C, Yan T, Omar S, Musa T (2003). Implementing Network-RTK: the SydNET CORS infrastructure, SatNav 2003, the 6th International Symp. On Satellite Nav. Tech. Including Mobile Pos. \& Location Services, 22-25, July, Melbourn, Australia.
Roberts C, Zhang K, Rizos C, Kealy A, Ge L, Ramm P, Hale M, Kinlyside D, Harmcombe $P$ (2004). An investigation of improved atmospheric modelling for large scale high-precision positioning based on GNSS CORS networks in Australia, J. GPS, 3: 218-225

URL 1 (2010). http://www.ngs.noaa.gov/CORS. Continously Operating Reference Station (CORS).

URL 2. (2010).http://www.cors.com.au/technical-info/cors-network. South Australian CORS Network

Vollath U, Deking A, Landau H, Pagels C, Wagner B (2000). Multi-Base RTK Positioning using Virtual Reference Stations, Proceedings of the 13th International Technical Meeting of the Satellite Division of the Institute of Navigation, Salt Lake City, Utah, USA, September.

Vollath U, Deking A, Landau H, Pagels C (2001). Long Range RTK Positioning using Virtual Reference Stations, Proceedings of the International Symposium on Kinematic Systems in Geodesy, Geomatics and Navigation, Banff, Canada, June.

Vollath U, Landau H, Chen X (2002). Network RTK - Concept and Performance, Proceedings of the GNSS Symposium, Wuhan, China, November.

Vollath U, Landau H, and Chen X (2003a). Network RTK versus Single Base RTK - Understanding the Error Characteristics, Proceedings of the 15th International Technical Meeting of the Satellite Division of the Institute of Navigation, Portland, Oregon, USA, September.

Vollath U, Sauer K, Amarillo F, Pereira J (2003b). Three or Four CarrierHow Many are Enough?, Proceedings of the ION GPS/GNSS Satellite meeting, September 9-12, Portland, Oregon, USA, pp. 14701477.

Vollath U, Patra R, Chen X, Landau H, Allison T (2004). Galileo/Modernized GPS: A New Challenge to Network RTK, Proceedings of the ION GPS/GNSS Satellite meeting, September, Long Beach, California, USA, pp. 21-24.

Wanninger $L$ (1999). The Performance of Virtual Reference Stations in Active Geodetic GPS-networks under Solar Maximum Conditions, Proceedings of the National Technical Meeting of the Satellite Division of the Institute of Navigation, ION GPS/1999 (September 1999, Nashville, USA), pp. 1419-1427.

Wübbena G, Willgalis S (2001). State Space Approach for Precise Real Time Positioning in GPS Reference Networks, International Symp. On Kinematic Systems on Geodesy, Geomatics and Navigation, KIS01, 5-8 June, Banff, Canada.

Wübbena G, Bagge A, Schmitz M (2001). Network-Based Techniques for RTK Applications, the GPS Symposium, GPS JIN 2001, GPS Society, Japan Institute of Navigation, 14-16 Nov., Tokyo, Japan.

Wanninger L (2002). Virtual Reference Stations for Centimeter-Level Kinematic Positioning, Proceedings of ION GPS, pp.1400-1407, Portland, Oregon, USA.

Wübbena G, Schmitz M, Bagge A (2004). Precise Kinematic GPS Processing and Rigorous Modeling of GPS in a Photogrammetric Block Adjustment, Geo++® GmbH, D-30827 Garbsen, Germany. 